\title{
QUALIDADE DOS FRUTOS DO PEQUIZEIRO SUBMETIDOS A DIFERENTES TEMPOS DE COZIMENTO
}

\author{
Quality Caryocar brasiliense Camb. fruits submitted to different cooking times
}

\author{
Gilma Auxiliadora Santos Gonçalves' ${ }^{1}$ Eduardo Valério de Barros Vilas Boas², Jaime Vilela de Resende², \\ Andrelisa Lina de Lima Machado ${ }^{3}$, Brígida Monteiro VilasBoas ${ }^{4}$
}

\begin{abstract}
RESUMO
O pequi é consumido tradicionalmente cozido, podendo sofrer influência desse processo. Objetivou-se, neste trabalho, avaliar o efeito de diferentes tempos de cozimento sobre a qualidade do pequi. Os frutos oriundos do Norte de Minas Gerais foram selecionados, lavados, sanificados, descascados e submetidos a diferentes tempos de cozimento $(0,5,10,15,20,25,30,35$ e 40 minutos). As análises foram realizadas no mesocarpo interno e na água de cozimento. Com o aumento do tempo de cozimento, observou-se, no fruto, diminuição da cor, firmeza e sólidos solúveis e dos minerais potássio, sódio, zinco e ferro, sendo esses minerais detectados na água. $\mathrm{O}$ cobre aumentou no mesocarpo interno e reduziu na água. Fósforo, cálcio, magnésio, manganês e enxofre não foram influenciados pelo tempo de cozimento. Vitamina $\mathrm{C}$, carotenóides totais e $\beta$-caroteno diminuíram proporcionalmente ao tempo de cozimento e desses, apenas a vitamina $\mathrm{C}$ foi encontrada na água de cozimento. Conclui-se que, mesmo com 40 minutos de cozimento, o pequi continua sendo importante fonte de nutrientes.
\end{abstract}

Termos para indexação: Frutas do cerrado, valor nutricional, minerais, vitaminas.

\begin{abstract}
Caryocar brasiliense Camb. fruits is traditionally consumed cooked; and may suffer influences from this process. Thus, the objective of this work was to evaluate the effect of different times of cooking on the quality of this fruit. The fruits from North of Minas Gerais (Brazil) were selected, washed, sanitized, peeled and submitted to different times of cooking $(0,5,10,15,20,25,30$, 35 and 40 minutes). The analyses were carried out at the internal mesocarp and in the cooking water. With the increase of cooking time, decrease of color, firmness and the minerals potassium, sodium, zinc and iron decreased in the fruit and were detected in the water. The copper increased in internal mesocarp and reduced in the water. Potassium, sodium, zinc and iron decreased in the fruit with increased time of cooking and were detected in the water. Copper increased in the internal mesocarp and decreased in water. Phosphorus, calcium, magnesium, manganese and sulfur were not influenced by cooking time. Vitamin C, total carotenoids and betacarotene decreased to the time of cooking and of these, only vitamin $\mathrm{C}$ was found in the cooking water. It was concluded that even with 40 minutes of cooking these fruits continues as an important source of nutrients.
\end{abstract}

Index terms: Savana fruit, nutricional value, minerals, vitamins.

(Recebido em 24 de outubro de 2008 e aprovado em 6 de julho de 2010)

\section{INTRODUÇÃO}

O Cerrado apresenta uma rica biodiversidade vegetal, salientando-se frutos com elevado potencial para a alimentação humana. Dentre as frutíferas nativas desse bioma, o pequizeiro (Caryocar brasiliense Camb.) merece atenção especial, tanto por sua elevada ocorrência como pelas características sensoriais e nutricionais de seus frutos, que contribuem para o suprimento de parte das exigências nutricionais da população.

$\mathrm{O}$ fruto, com cerca de $10 \mathrm{~cm}$ de diâmetro e aproximadamente $120 \mathrm{~g}$, com 1 a 4 pirênios (mesocarpo interno, endocarpo espinhoso e semente) é composto pelo mesocarpo externo, que é coriáceo carnoso, mesocarpo interno amarelo-claro, carnoso, rico em nutrientes, e envolve uma camada de espinhos endocárpicos, finos e rígidos e amêndoa branca ou semente (Barradas, 1973).

Vários trabalhos enfatizam o valor nutricional dessa frutífera, por ser altamente calórica, rica em lipídeos, proteínas, fibras, cinzas, glicídios e com destaque para seu alto teor de carotenóides, vitaminas A (beta-caroteno) e vitamina C (Ramos et al., 2001; Oliveira et al., 2006; Rodrigues et al., 2007; Souza et al., 2007; Vera et al., 2007; Damiani et al., 2008).

Com aroma inconfundível e coloração amarelada, o caroço com a polpa (mesocarpo interno) é utilizado

${ }^{1}$ Instituto Federal de Educação Ciência e Tecnologia - Sudeste de Minas Gerais - Rua Monsenhor José Augusto - 204 - São José - $36205-018$ Barbacena, MG - gilma.goncalves@ifsudestemg.edu.br

'Universidade Federal de Lavras/UFLA - Departamento de Ciência dos Alimentos/DCA - Lavras, MG

${ }^{3}$ Universidade Federal de Lavras /UFLA - Lavras, MG

${ }^{4}$ Instituto Federal de Educação Ciência e Tecnologia - Sul de Minas Gerais Escola - Machado, MG 
tradicionalmente cozido com arroz, com galinha, com água e sal, batido com leite ou no preparo de pamonha, vitamina, chocolate, bolos e doces, dentre outros (Lorenzi, 2000).

Além de seu uso no preparo de pratos típicos, o pequi, serve de matéria-prima para agroindústrias regionais de conservas (Ferreira \& Junqueira, 2009), temperos, licores e congelados. Embora essa iniciativa seja uma possibilidade de melhoria da renda das comunidades do Cerrado, demanda o domínio de tecnologias apropriadas para a conservação do pequi.

A preparação doméstica tem grande influência na qualidade dos alimentos, podendo mudar atributos sensoriais e valor nutritivo de maneira positiva ou negativa (Bernhardt \& Schlich, 2006).

Muitos dos dados de tabelas de composição nutricional representam os alimentos crus, quando muitos alimentos são consumidos após serem processados, armazenados e/ou preparados de várias maneiras, o que pode afetar, ao menos em parte, sua composição química.

Assim, é fundamental a determinação do efeito de diferentes condições de preparo de um alimento, quando se afirma que o mesmo possui alto valor nutritivo. Adicionalmente, estudos reportam a influência do tempo de cozimento na qualidade sensorial e nutricional de alimentos vegetais (Coelho et al., 2009; Coelho et al., 2009; Oliveira \& Moraes, 2009).

O pequi, embora de grande potencial nutritivo, é pouco estudado e, como é consumido tradicionalmente cozido ou após algum tipo de processamento térmico que leva a perdas, o presente trabalho foi realizado com a finalidade de analisar o efeito de diferentes tempos de cozimento sobre a qualidade física, química e físicoquímica, indicadoras da qualidade do pequi.

\section{MATERIAL E MÉTODOS}

\section{Obtenção dos frutos e preparo das amostras}

Os pequis foram adquiridos em Bocaiúva, Norte de Minas Gerais, em janeiro de 2007, época da safra e transportados para o Laboratório de Pós-Colheita de Frutas e Hortaliças, no Departamento de Ciência dos Alimentos, da Universidade Federal de Lavras (UFLA). Foram lavados em água corrente, com detergente neutro, enxaguados para eliminação de sujidades superficiais, provenientes do campo, e selecionados quanto à ausência de defeitos, pragas e podridões. Em seguida, foram sanificados (hipoclorito de sódio $200 \mathrm{mg} .100 \mathrm{~g} \mathrm{~g}^{-1}$, por 20 minutos), descascados manualmente com facas para a obtenção dos pirênios, os quais foram submetidos ao processo de cozimento em água
(300 $\mathrm{g} \mathrm{L}^{-1}$ ), em panelas de aço inoxidável tampadas, por diferentes tempos $(0,5,10,15,20,25,30,35$ e 40 minutos).

Após o resfriamento dos frutos, ao ar e em temperatura ambiente, foram realizadas as análises de firmeza, cor, umidade e extração da vitamina $\mathrm{C}$ (fruto e água). As amostras remanescentes foram congeladas em nitrogênio líquido e estocadas, a $-80^{\circ} \mathrm{C}$, para a realização posterior das demais análises.

Foi coletado um volume médio de $100 \mathrm{~mL}$ da água de cada tempo de cozimento e estocado em freezer para a realização das análises de $\beta$-caroteno, carotenóides totais e minerais.

\section{Análises}

Coloração: Determinada em lados opostos dos pirênios, utilizando-se o colorímetro Minolta CR-400, com a determinação no modo CIE L*a*b*. As coordenadas a* $\mathrm{e} b^{*}$ foram usadas para calcular o $h^{\circ}$ (ângulo da tonalidade) e o $\mathrm{C}^{*}$ (cromaticidade), a partir das seguintes fórmulas: $\mathrm{h}^{\mathrm{o}}=\tan ^{-1}\left(\mathrm{~b}^{*} / \mathrm{a}^{*}\right)$ e $\mathrm{C}^{*}=\left(\mathrm{a}^{* 2}+\mathrm{b}^{* 2}\right)^{1 / 2}$, respectivamente (Minolta, 1998).

Carotenóides totais: Extraídos com hexano, sendo a cor lida em espectrofotômetro a $450 \mathrm{~nm}$, segundo o Instituto Adolfo Lutz (1985). Os resultados foram expressos em miligramas de carotenóides totais por $100 \mathrm{~g}$.

$\beta$-caroteno: Extraído com acetona:hexano (4:6) e determinado segundo Nagata \& Yamashita (1992). O teor de $\beta$-caroteno foi expresso em miligramas por $100 \mathrm{~g}$, após o seu equacionamento: $\beta$-caroteno $=0,216 \mathrm{~A}_{663}-1,22 \mathrm{~A}_{645}{ }^{-}$ $0,304 \mathrm{~A}_{505}+0,452 \mathrm{~A}_{455}$, sendo: $\mathrm{A}_{663}, \mathrm{~A}_{645}, \mathrm{~A}_{505} \mathrm{e} \mathrm{A}_{453}$, leituras de absorbância nos respectivos comprimentos de onda. Vitamina C: Determinada pelo método colorimétrico, utilizando-se 2,4 dinitrofenilhidrazina, segundo Strohecker \& Henning (1967). Os resultados foram expressos em mg de ácido ascórbico por $100 \mathrm{~g}$ de polpa.

Firmeza: Determinda com texturômetro Stable Micro System modelo TAXT2i, utilizando-se a sonda tipo agulha $\mathrm{P} / 2 \mathrm{~N}$ ( $2 \mathrm{~mm}$ de diâmetro), numa velocidade de $5 \mathrm{~mm} / \mathrm{s}$ e uma distância de penetração de $3 \mathrm{~mm}$, valores esses previamente fixados. Foi usada uma plataforma HDP/90 como base. A firmeza foi expressa em Newton (N).

Sólidos solúveis (SS): Usou-se refratômetro digital ATAGO PR-100 com compensação de temperatura automática e os resultados expressos $\mathrm{em}^{\circ} \mathrm{Brix}$, conforme a Association of Official Agricultural Chemists - AOAC (1992).

Minerais: Determinados no Laboratório de Análise Foliar, no Departamento de Química da UFLA. Os extratos foram obtidos por digestão nitroperclórica e determinados segundo Malavolta et al. (1989). O fósforo foi determinado por colorimetria, segundo método da AOAC (1992); o enxofre por turbodimetria; o potássio e 
o sódio por fotometria de chama; cálcio, magnésio, manganês, zinco, cobre e ferro, por espectrofotometria de absorção atômica.

O delineamento experimental foi inteiramente casualisado (DIC) e as análises estatísticas das variáveis físicas, químicas e físico-químicas foram realizadas com o auxílio do programa Sisvar (Ferreira, 2000). Após a análise de variância dos resultados obtidos, observou-se o nível de significância do teste $\mathrm{F}$. As médias de cada tempo de cozimento foram submetidas à regressão polinomial, em que os modelos foram selecionados de acordo com a significância do teste $\mathrm{F}$ de cada modelo e com o coeficiente de determinação.

\section{RESULTADOS E DISCUSSÃO}

As variáveis $L^{*}, h^{\circ}$ e $C^{*}$ (Figura 1 A, B e C) foram influenciados pelo tempo de cozimento, indicando diminuição da coloração amareloavermelhada do fruto.

A redução linear da coordenada $L^{*}$ indica tendência ao escurecimento do produto, ao longo do cozimento.
$\mathrm{O} \mathrm{h}^{\mathrm{o}}$ caracteriza a qualidade da cor (amarelo, vermelho, etc.) permitindo diferenciá-la. $\mathrm{O}$ valor de $\mathrm{h}^{\mathrm{o}}$ encontrado para o pequi cru foi de 71,65 , correspondendo à cor amarelo-avermelhado. Pelo pequeno aumento dessa variável observado na Figura 1 B observa-se redução da cor avermelhada e tendência ao amarelo. A cromaticidade descreve a intensidade de uma tonalidade de cor. Quanto mais alto o valor de $C^{*}$ mais intensa é a cor. A redução linear da cromaticidade, ao longo do cozimento, sugere diminuição da intensidade da cor do fruto, provavelmente provocada pela degradação dos pigmentos carotenóides característicos do fruto.

Resultados semelhantes foram encontrados por Dubois et al. (2007) que detectaram diminuição na intensidade do brilho e da cor na polpa do tubérculo oca (Oxalis tuberosa Mol.), submetido ao cozimento. Segundo Rodriguez-Amaya (1997), os carotenóides, pigmentos de coloração amarela, presentes no pequi, são suscetíveis à isomerização e à oxidação durante processamento e armazenamento, tendo como consequências práticas a perda da cor e da atividade biológica.
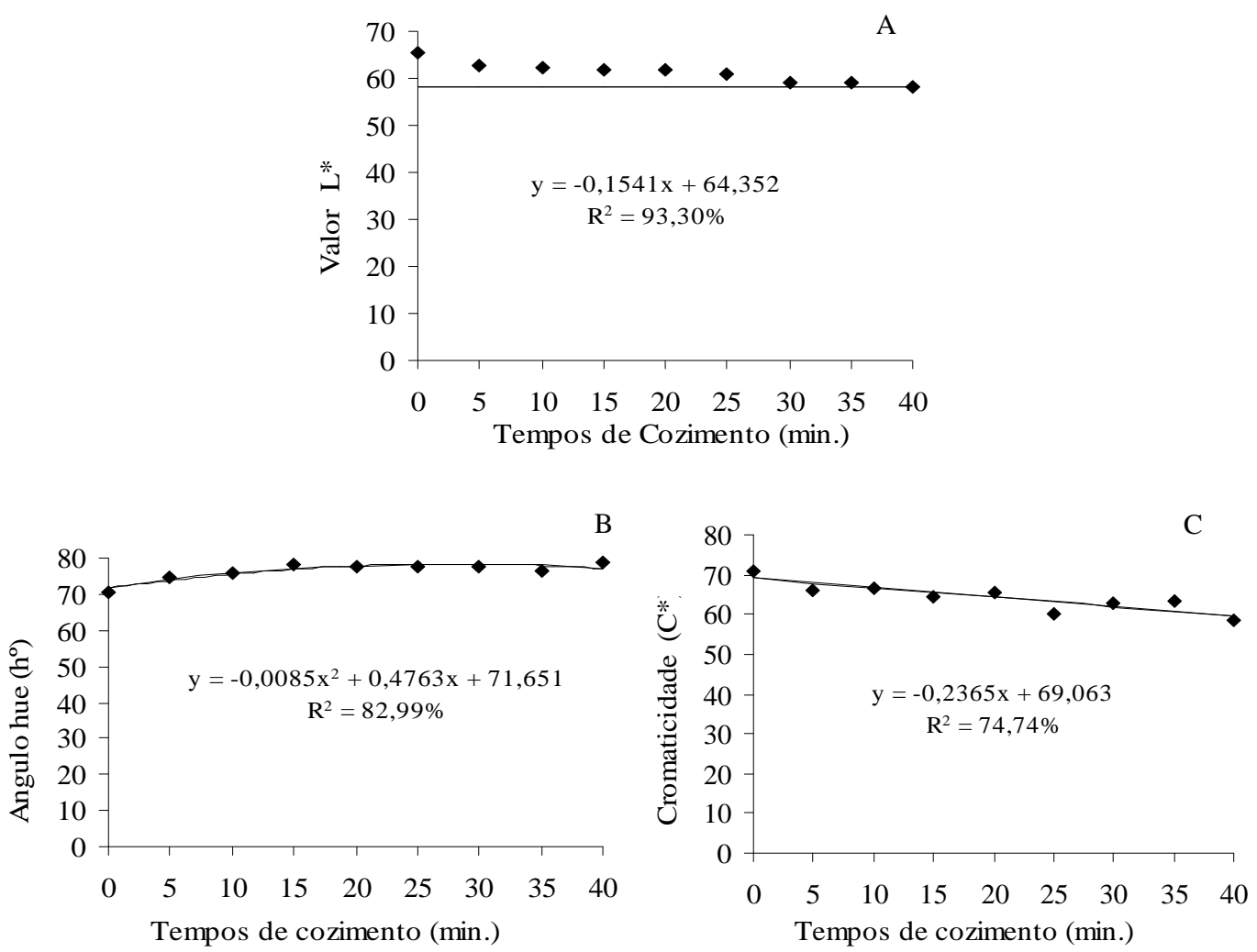

Figura 1 - Valores médios ajustados e equações de regressão das coordenadas: (A) L*; (B) Ângulo hue (ho) e (C) Cromaticidade $\left(\mathrm{C}^{*}\right)$ do pequi submetido a diferentes tempos de cozimento. 
O mesocarpo interno do pequi cru apresentou teor de carotenóides totais de $13,06 \mathrm{mg} .100 \mathrm{~g}^{-1}$, semelhante ao encontrado por Oliveira (2007), que foi de $14,5 \mathrm{mg} .100 \mathrm{~g} \mathrm{~g}^{-1}$. $\mathrm{O}$ teor de $\beta$-caroteno foi de $3,08 \mathrm{mg} .100 \mathrm{~g}^{-1}$. Estes componentes foram linearmente reduzidos ao longo do tempo de cozimento (Figura 2 A e B). Os resultados se correlacionam com a diminuição dos valores da coordenada $\mathrm{h}^{\mathrm{o}}$ (Figura $1 \mathrm{~B}$ ).

Ao se analisar a água de cozimento foram detectados valores de carotenóides inferiores a $0,1 \mathrm{mg} .100 \mathrm{~g}^{-1}$, equivalente a, aproximadamente, $1 \%$ do valor encontrado no pequi cru. Não foi detectada presença de $\beta$-caroteno na água de cozimento, o que pode ser justificado pelo fato de esse componente ser insolúvel em água.

Ramos et al. (2001) também observaram perda de carotenóides após 30 minutos de cozimento de pequi. As perdas foram, em média, de 30,25\% de carotenóides totais e $2,81 \%$ de $\beta$-caroteno. As diferenas detectadas nas perdas, provavelmente, foram devido a diferentes procedimentos durante o cozimento (método de cocção, quantidade de água, tempo), técnicas de extração e determinação.

Pesquisas com outros alimentos também tm apontado perdas de carotenóides provocadas pelo cozimento. Pinheiro-Santana et al. (1998) relataram perdas de $39,87 \%$ nos carotenóides totais e $22 \%$ no $\beta$-caroteno de cenouras cozidas por fervura. Enquanto Bianchini $\&$ Penteado (1998) observaram perdas de $33,23 \%$ no $\beta$-caroteno de pimentões amarelos (Capsicum annuиm, L.), após 10 minutos a $100^{\circ} \mathrm{C}$.

$\mathrm{O}$ teor de vitamina $\mathrm{C}$ presente no pequi cru foi de $91,89 \mathrm{mg} .100 \mathrm{~g}^{-1}$, semelhante ao detectado por Rodrigues (2005) (98,4 mg.100 g $\left.{ }^{-1}\right)$ e por Vilas-Boas (2004) (105 mg.100 g-1).
A vitamina $\mathrm{C}$ foi influenciada ( $\mathrm{p}<0,05)$, tendo seus valores diminudos com o aumento do tempo de cozimento, conforme se observa no gráfico da Figura $3 \mathrm{~A}$. Na água de cozimento foi detectada vitamina $\mathrm{C}$ apenas a partir dos 15 minutos de cozimento $\left(2,95 \mathrm{mg} .100 \mathrm{~g}^{-1}\right)$, a qual aumentou linearmente com o aumento do tempo (Figura $3 \mathrm{~B}$ ).

A grande perda de vitamina $C$, durante os 40 minutos de cozimento do pequi, refora a grande sensibilidade desse nutriente ao processamento. Observa-se que, com o avanço do tempo de cozimento (Figura $3 \mathrm{~A}$ ), parte do ácido ascórbico foi degradada e parte foi retida na água de cozimento (Figura 3 B), o que pode não representar perdas no caso do pequi, pois esse geralmente cozido com arroz, frango ou outro alimento, permitindo o aproveitamento da vitamina $\mathrm{C}$ lixiviada.

Devido alta solubilidade do ácido ascórbico na gua, pode-se supor que a perda por lixiviação seja, em parte, responsável pela perda dessa vitamina (Kumar \& Albersberg, 2006), o que foi comprovado no presente trabalho.

No entanto, a vitamina $\mathrm{C}$ um nutriente especialmente sensível a condições de processamento, tais como: temperatura, $\mathrm{pH}$, conteúdo de água, presença de substâncias antioxidantes, oxigênio e íons metálicos catalíticos (Burg \& Fraile, 1995).

A firmeza e o teor de sólidos solúveis do pequi foram afetados pelo tempo de cozimento. Observou-se redução linear dessas variáveis nos pirênios, tanto maior a redução quanto mais longo o tempo de cozimento (Figura 4 A e B).

A diminuição da firmeza observada aps o cozimento pode ser atribuída às modificações nos polissacarídeos da
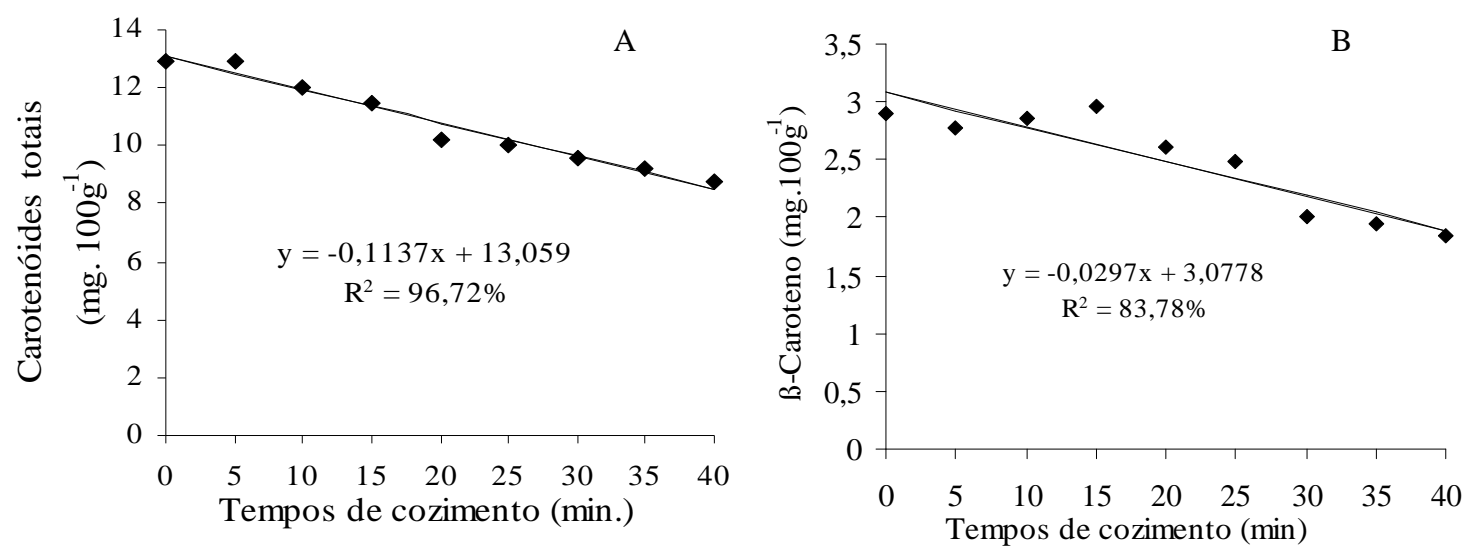

Figura 2 - Valores médios ajustados e equações de regressão dos teores de: (A) carotenóides totais e (B) $\beta$-caroteno do pequi submetido a diferentes tempos de cozimento.

Ciênc. agrotec., Lavras, v. 35, n. 2, p. 377-385, mar./abr., 2011 


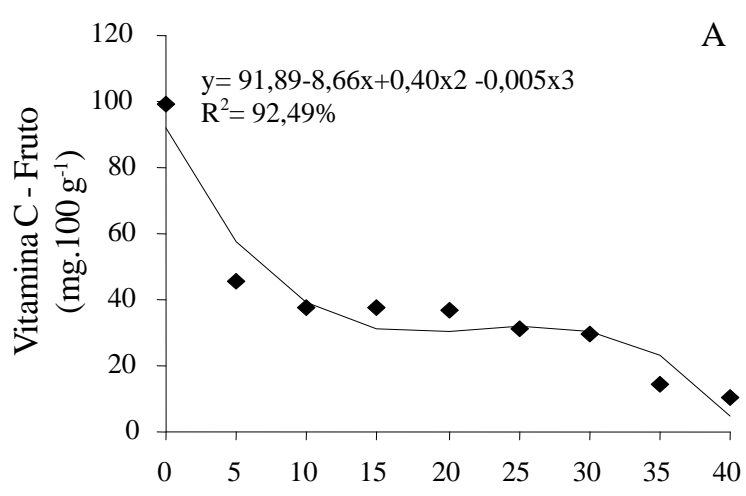

Tempos de cozimento (min.)

A

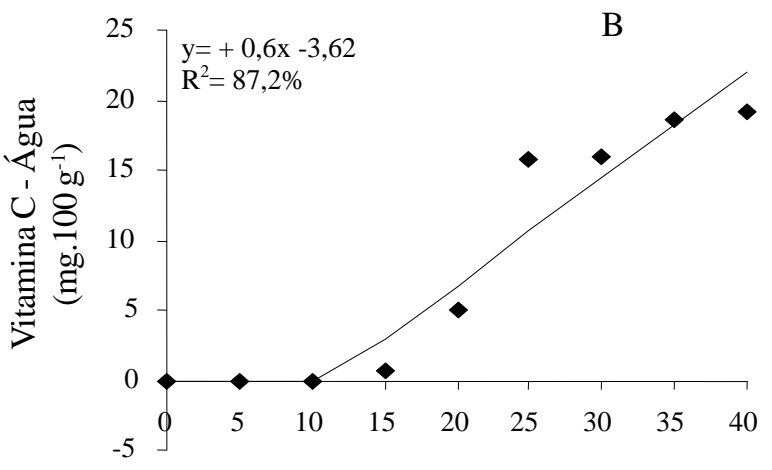

Tempos de cozimento (min.)

Figura 3 - Valores médios ajustados e equações de regressão dos teores de: (A) vitamina C do fruto e (B) vitamina C da água de cozimento do pequi submetido a diferentes tempos de cozimento.
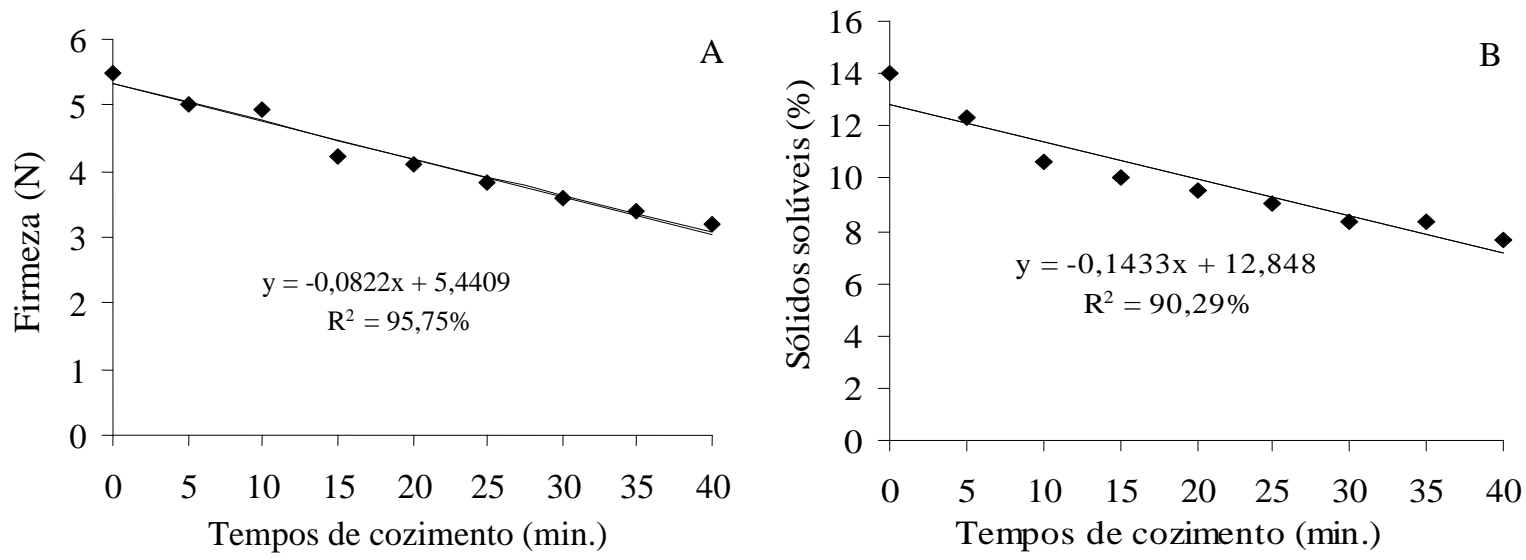

Figura 4 - Valores médios ajustados e equações de regressão dos teores de: (A) firmeza e (B) sólidos solúveis do pequi submetido a diferentes tempos de cozimento.

parede celular que são solubilizados, levando degradação da mesma e a perda de adesão das clulas descrita para outros frutos e vegetais durante os processamentos térmicos (Ferreira et al., 2001).

O valor de sólidos solúveis reduziu linearmente, de $12,84 \%$ no pequi cru, para $7,11 \%$, após 40 minutos de cozimento (Figura 4 B). Essa queda pode ser explicada pela difusão simples desses, aps terem sido solubilizados na água de cozimento. Redução nos teores de sólidos solúveis com o cozimento também foi observada por Lima et al. (2003), em ervilhas (Pisum sativum $\mathrm{L}$.).

Os minerais fósforo, cálcio, magnésio, enxofre e manganês no foram significativamente influenciados pelo cozimento (Tabela 1). Não foi detectada a presença desses minerais na água de cozimento, ao longo dos 40 minutos de tratamento.

Tabela 1 - Teores médios de minerais do pequi, durante 40 minutos de cozimento (mg.100 g ${ }^{-1}$ matéria integral).

\begin{tabular}{ccccc}
\hline Fósforo & Cálcio & Magnésio & Enxofre & Manganês \\
\hline 30 & 90 & 40 & 60 & 0,40 \\
\hline
\end{tabular}

Pequena ou nenhuma perda desses minerais pelo cozimento também foram observadas por outros autores, como Santos et al. (2003) e Ferreira et al. (2006) em folhas de brócolis, couve-flor e couve (Brassica oleracea L.). A não dissolução de minerais na água de cozimento pode ser devido à presença de compostos ligantes dos 
minerais a constituintes do alimento, que impedem sua perda para a água de cocção (Pedrosa \& Cozzolino, 2001).

Já os minerais potássio, sódio, ferro, zinco e cobre foram influenciados pelo tempo de cozimento. Observouse redução linear dos primeiros e elevação linear do último, tanto maior quanto mais longo o tempo de cozimento (Figuras 5 A e C; 6 A, C e E).

Resultados coerentes foram observados na água de cozimento que apresentou aumento linear dos minerais potássio, sódio e zinco, proporcional ao aumento do tempo de cozimento (Figuras 5 B e D; 6 D). O ferro apresentou comportamento quadrático, tendendo à elevação (Figura $6 \mathrm{~B}$ ). $\mathrm{O}$ teor de cobre na água de cozimento foi linearmente reduzido ao longo do tempo de exposição (Figuras 6 F ).

Expressivas reduções nos minerais, provocadas pelo cozimento de diferentes alimentos, também têm sido reportadas: Kawashima \& Soares (2005), em espinafre
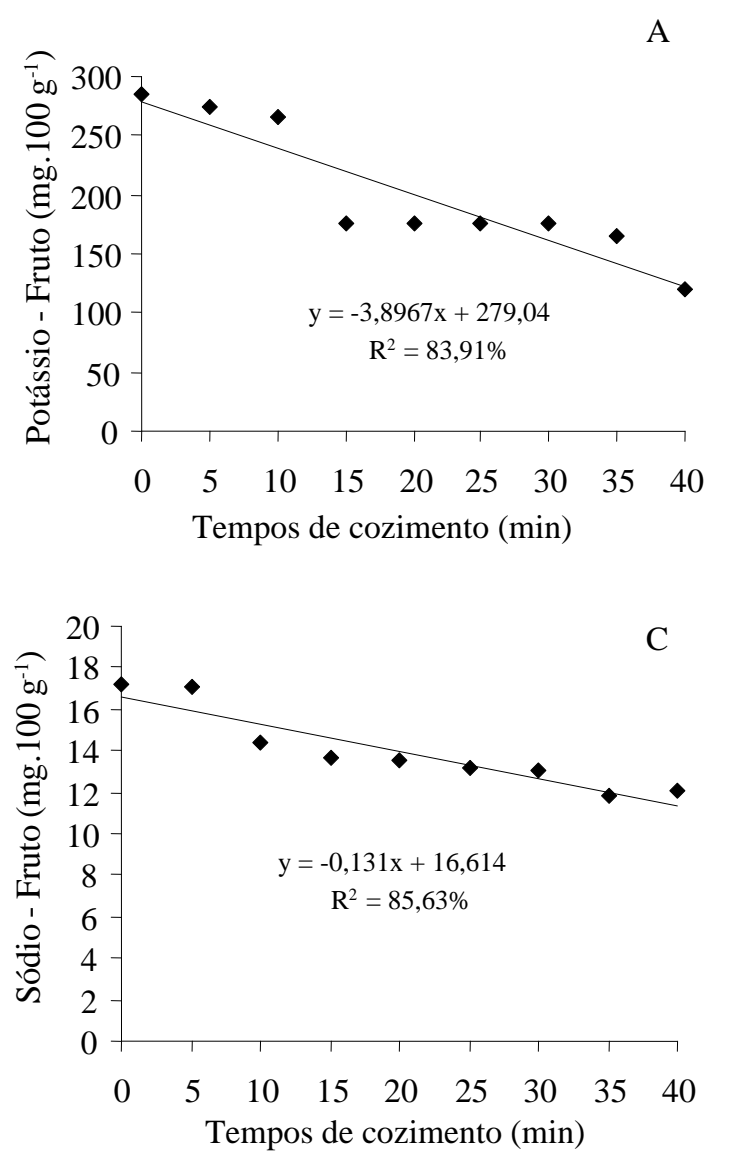

(Tetragonia expansa Murray) (53\% de potássio, 57\% de sdio, $35 \%$ de zinco e $5 \%$ de ferro); Ferreira et al. (2006), em grão-de-bico (Cicer arietinum L.) (29,44\% de potássio e $8 \%$ de ferro); Santos et al. (2003), em couve e em brócolis (56,5\% e $27,13 \%$ de potássio, respectivamente) e Sebasti et al. (2001), em lentilhas (Lens esculenta Moench.) (28,9\% e $40,7 \%$ de ferro para cozimento domstico e processamento industrial, respectivamente).

Segundo Tannembaum et al. (1993), a principal operação que origina perdas de substâncias minerais a lixiviação, que arrasta parte dos minerais solúveis. No caso do pequi, os minerais lixiviados podem ser aproveitados, pois o mesmo tradicionalmente consumido cozido com arroz, frango e outros alimentos.

$\mathrm{O}$ teor de cobre do pequi cru aumentou linearmente ao longo do cozimento (Figura $6 \mathrm{E}$ ) e reduziu na água ao longo dos 40 minutos de exposição (Figura 6 F). Isso, provavelmente, explica o aumento desse mineral no fruto ao longo do cozimento.
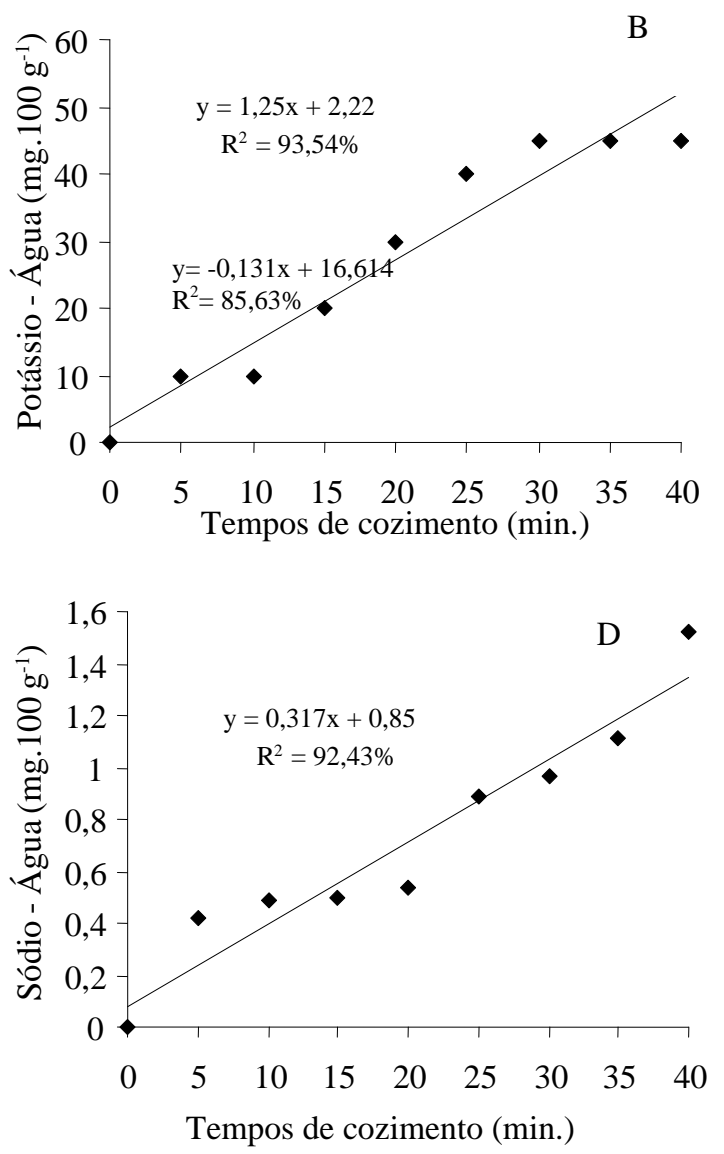

Figura 5 - Valores médios ajustados e equações de regressão dos teores minerais do pequi submetido a diferentes tempos de cozimento; (A) potássio do fruto; (B) potássio da água de cozimento; (C) sódio do fruto e (D) sódio da água de cozimento.

Ciênc. agrotec., Lavras, v. 35, n. 2, p. 377-385, mar./abr., 2011 

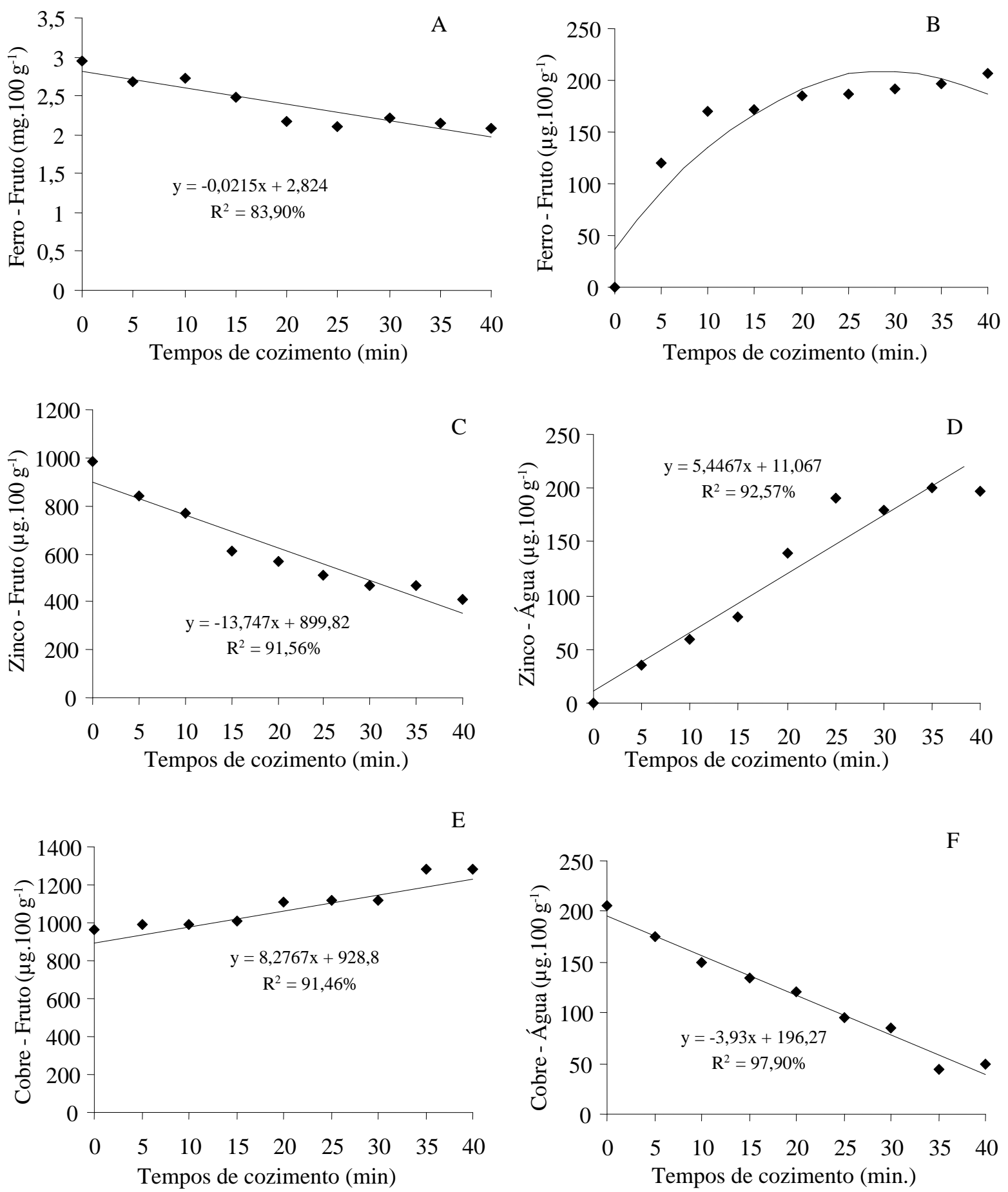

Figura 6 - Valores médios ajustados e equações de regressão dos teores de minerais do fruto e da água de cozimento do pequi submetido a diferentes tempos de cozimento. (A) ferro do fruto; (B) ferro da água de cozimento; (C) zinco do fruto; (D) zinco da água de cozimento; (E) cobre do fruto e (F) cobre da água de cozimento. 


\section{CONCLUSÕES}

Compostos termolábeis do pequi, como vitamina $\mathrm{C}$, carotenóides totais e $\beta$-caroteno, têm seus teores diminuídos com o aumento do tempo de cozimento, assim como a cor, os sólidos solúveis e a firmeza, embora a redução dessa última seja desejável para o consumo do fruto por torná-lo macio.

Parte dos minerais do pequi (cálcio, fósforo, magnésio, manganês e enxofre) são retidos no fruto, mesmo após 40 minutos de cozimento, enquanto outros (potássio, sódio, ferro e zinco) são lixiviados para a água de cozimento à medida que se aumenta o tempo de exposição ao calor.

A lixiviação de compostos para a água de cozimento evidencia a importância de seu aproveitamento na alimentação e o fruto, mesmo após 40 minutos de cozimento, mantém-se importante fonte de nutrientes.

\section{AGRADECIMENTOS} financeiro.

Ao CNPq, CAPES e FAPEMIG pelo apoio

\section{REFERÊNCIAS BIBLIOGRÁFICAS}

ASSOCIATION OF OFFICIAL AGRICULTURAL CHEMISTS. Official methods of the Association of the Agricultural Chemists. 15.ed. Washington, 1992. 2v.

BARRADAS, M.M. Informações sobre floração, frutificação e dispersão do piqui Caryocar brasiliense Camb. (Caryocaraceae). Ciência e Cultura, São Paulo, v.24, n.11, p.1063-1072, nov. 1973.

BERNHARDT, S.; SCHLICH, E. Impact of different cooking methods on food quality: Retention of lipophilic vitamins in fresh and frozen vegetables. Journal of Food Engineering, v.77, n.2, p.327-333, nov. 2006.

BIANCHINI, R.; PENTEADO, M.V.C. Carotenóides de pimentões amarelos (Capsicum annuum L.). Caracterização e verificação de mudanças com o cozimento. Cincia e Tecnologia de Alimentos, Campinas, v.18, n.3, p.283-288, 1998.

BURG, P.; FRAILE, P. Vitamin C destruction during the cooking of a potato dish. Lebensm.-Wiss. u.Technology, London, v.28, n.1, p.506-514, 1995.

COELHO, C.M.M.; BORDIN, L.C.; SOUZA, C.A.; MIQUELLUTI, D.J.; GUIDOLIN, A.F. Tempo de cocção de grãos de feijão em função do tipo d'água. Ciência e Agrotecnologia, Lavras, v.33, n.2, p.560-566, mar./abr., 2009.
COELHO, S.R.M.; PRUDENCIO, S.H.; NÓBREGA, L.H.P.;

LEITE, C.F.R. Alterações no tempo de cozimento e textura dos grãos de feijão comum durante o armazenamento. Ciência e Agrotecnologia, Lavras, v.33, n.2, p.539-544, mar./abr., 2009.

DAMIANI, C.; VILAS-BOAS, E.V. de B.; PINTO, D.M.; RODRIGUES, L.J. Influência de diferentes temperaturas na manutenção da qualidade de pequi minimamente processado. Ciência e Agrotecnologia, Lavras, v.32, p.203-212, 2008.

DUBOIS, M.; SAVAGE, G.P.; MARTIN, R.J. The effect of cooking on the composition and colour of New Zealand grown oca. Food Chimistry, London, v.104, p.768-773, 2007.

FERREIRA, A.C.P.; BRAZACA, S.G.C.; ARTHUR,A. Alterações químicas e nutricionais do grão-de-bico (Cicer arietinum L.) cru irradiado e submetido à cocção. Ciência e Tecnologia de Alimentos, Campinas, v.26, n.1, p.80-88, 2006.

FERREIRA, D.; BARROS, A.; COIMBRA, M.A.; DELGADILLO, I. Use of FT-IR spectroscopy to follow the effect of processing in cell wall polysaccharide extracts of a sun-dried pear. Carbohydrate Polymers, New York, v.45, p.175-182, 2001.

FERREIRA, D.F. Sistema para Análise de Variância para Dados Balanceados (SISVAR). Lavras: UFLA, 2000. 92p.

FERREIRA, L.C.; JUNQUEIRA, R.G. Condições higiênicosanitárias de uma indústria de processamento de conservas de polpa de pequi na região norte do Estado de Minas Gerais. Ciência e Agrotecnologia, Lavras, v.33, Edição Especial, p.1825-1831, 2009.

INSTITUTO ADOLFO LUTZ. Normas Analíticas do Instituto Adolfo Lutz: métodos químicos e físicos para análise de alimentos. 3.ed. São Paulo, 1985. v.1.

KAWASHIMA, L.M.; VALENTE-SOARES, L.M. Effect of blanching time on selective mineral elements extraction from the spinach substitute (Tetragonia expansa) commonly used in Brazil. Ciência e Tecnologia de Alimentos, Campinas, v.25, n.3, p.419-424, set. 2005.

KINCAL, N.S.; GIRAY, C. Kinetics of ascorbic acid degradation in potato blanching. International Journal of Food Science and Technology, v.22, n.4, p.249-254, 1987. 
KUMAR, S.; ALBERSBERG, B. Nutrient retention in foods after earth-oven cooking compared to other forms of domestic cooking: vitamins. Journal of Food Composition and Analysis, New York, v.19, n.3, p.311-320, 2006.

LIMA, E.D.P.A.; JERÔNIMO, E.S.; LIMA, C.A.A.; GONDIM, P.J.S.; ALDIGRE, M.L.; CAVALGANTE, L.F.

Physical and chemical characteristics of green grains of cowpea cultivars and lines for processing and preservation. Revista Brasileira de Engenharia Agrícola e Ambiental, Campina Grande, v.7, n.1, p.445450, 2003.

LORENZI, H. Árvores brasileiras: manual de identificação e cultivo de plantas arbóreas nativas do Brasil. Nova Odessa: Plantarum, 2000. v.1.

MALAVOLTA, E.; VITTI, G.C.; OLIVEIRA, S.A. Avaliação de estado nutricional das plantas. Piracicaba: Potafos, 1989. 201p.

MINOLTA. Precise color comunication: color control from perception to instrumentation. Sakai, 1998. Encarte.

NAGATA, M.; YAMASHITA, I. Simple method for simultaneous determination of chlorophyll and carotenoids in tomato fruit. Nippon Shokuhin Kogyo Gakkaishi, Tokyo, v.39, n.10, p.925-928, Oct. 1992.

OLIVEIRA, M.A. de; MORAES, P.S.B. Características físico-químicas, cozimento e produtividade de mandioca cultivar IAC 576-70 em diferentes épocas de colheita. Ciência e Agrotecnologia, Lavras, v.33, n.3, p.837-843, maio/jun., 2009.

OLIVEIRA, M.N.S.; GUSMÃO, E.; LOPES, P.S.N.; SIMÕES, M.O.N.; RIBEIRO, L.M.; DIAS, B.A.S. Estádio de maturação dos frutos e fatores relacionados aos aspectos nutritivos e de textura da polpa de pequi (Caryocar brasiliense Camb.). Revista Brasileira de Fruticultura, Jaboticabal, v.28, n.3, p.271-275, 2006.

PEDROSA, L.F.C.; COZZOLINO, S.M.F. Composição centesimal e de minerais de mariscos crus e cozidos da cidade de Natal/RN. Ciência e Tecnologia de Alimentos, Campinas, v.21, n.2, p.154-157, 2001.

PINHEIRO-SANTANA, H. M.; STRINGHETA, P. C.; BRANDÃO, S. C. C.; PÁEZ, H. H.; QUEIRÓZ, V. M. V. Evaluation of total carotenoids, $\alpha$ - and $\beta$-carotene in carrots (Daucus carota L.) during home processing. Ciência e Tecnologia de Alimentos, v. 18, n. 1, 1998.

RAMOS, M.I.; UMAKI, M.C.S.; HIANE, P.A. Efeito do cozimento convencional sobre os carotenóides próvitamínicos A da polpa de pequi (Caryocar brasiliense Camb). Revista de Nutrição, Campinas, v.19, n.1, p.23-32, 2001.

RODRIGUEZ-AMAYA, D.B. Carotenoids and food preparation: the retention of provitamin A carotenoids in prepared, processed, and stored food: USAID, OMNI Project. [S.1.], 1997.

RODRIGUES, L.J.; VILAS-BOAS, E.V. de B.; PÍCCOLI, R.H.; PAULA, N.R.F. de; PINTO, D.M.; BOAS, B.M.V. Efeito do tipo de corte e sanificantes no amaciamento de pequi minimamente processado. Ciência $\mathbf{e}$ Agrotecnologia, Lavras, v.31, p.1793-1795, 2007.

SANTOS, M.A.T.; ABREU, C.M.P.; CARVALHO, V.D. Efeito de diferentes tempos de cozimento nos teores de minerais em folhas de brócolis, couve-flor e couve (Brassica oleracea L.). Ciência e Agrotecnologia, Lavras, v.27, n.3, p.597-604, maio/jun. 2003.

SEBASTIÁ, V.; BARBERÁ, R.; FARRÉ, R.; LAGARDA, $M$. Effects of legume processing on calcium, iron and zinc contents and dialysabilities. Journal of Science Food Agricultural, v.81, n.5, p.1180-1185, 2001.

SOUZA, É.C. de; VILAS-BOAS, E.V. de B.; BOAS, B.M.V.; RODRIGUES, L.J.; PAULA, N.R.F. de. Qualidade e vida útil de pequi minimamente processado armazenado sob atmosfera modificada. Ciência e Agrotecnologia, Lavras, v.31, p.1811-1817, 2007.

STROHECKER, R.; HENNING, H.M. Analisis de vitaminas: metodos comprobados. Madrid: $\mathrm{Paz}$ Montalvo, 1967. 428p.

TANNENBAUM, S.R.; YOUNG, V.R.; ARCHER, M.C. Vitaminas y mirerales. In: FENNEMA, O.R. Química de los alimentos. 2.ed. Zaragoza: Acribia, 1993. p.537-613.

VERA, R.; SOUZA, E.R.B.; FERNANDES, E.P.; NAVES, R.V.; CALIARI, M.; XIMENES, P.A. Caracterização física e química de frutos do pequizeiro (Caryocar brasiliense camb.) oriundos de duas regiões no estado de Goiás, Brasil. Pesquisa Agropecuária Tropical, Goiânia, v.37, n.2, p.93-99, 2007. 